\title{
Multiple minute digitate hyperkeratosis - a peculiar entity*
}

\author{
Inês Coutinho ${ }^{1}$ \\ Miguel Pinto Gouveia ${ }^{1}$ \\ Américo Figueiredo ${ }^{1}$
}

\author{
Ana Rita Gameiro ${ }^{1}$ \\ José Carlos Cardoso ${ }^{1}$
}

DOI: http:/ /dx.doi.org/10.1590/abd1806-4841.20153440

\begin{abstract}
A bstract: Multiple minute digitate hyperkeratosis is a rare, non-follicular dermatosis, with fewer than 30 cases described worldwide. It can be either acquired or inherited in an autosomal dominant pattern. We describe the case of an 83-year old patient with life-long, multiple, digitate, milimetric lesions, and a positive family history for the same dermatosis.
\end{abstract}

Keywords: Dermatology; Genes, dominant; Keratosis

\section{INIRODUCTION}

Multiple minute digitate hyperkeratosis $(\mathrm{MMDH})$ is a rare, non-follicular, keratinization dermatosis of unknown etiology that can be either inherited (in what appears to be an autosomal dominant pattern) or acquired. ${ }^{1}$ There are fewer than 30 cases described in international literature. ${ }^{2}$

We herein report the case of a female patient presenting with a life-long history of a spiny dermatosis.

\section{CASE REPORT}

An 83-year-old woman presented with multiple, asymptomatic, non-follicular, skin-colored finger-like projections sparing the face, palms and soles (Figure $1)$. In the anterior thoracic wall, the lesions were flattened, with a yellow hue, forming $1-3 \mathrm{~mm}$ crateriform papules (Figure 2).

They had developed over a period of 50 years; she had no other complaints and her physical exam was otherwise unremarkable. Apart from hypertension, she had no other comorbidites. These lesions had also affected her father, sister and daughter, since adulthood.
Biopsy of one of the crateriform papules showed ortho- and parakeratotic hyperkeratosis overlying a slightly acanthotic epidermis with a preserved granular layer and a very mild perivascular lymphocytic infiltrate in the upper dermis (Figures 3 and 4). Ancillary tests, including complete blood count, kidney and liver function, serum protein electrophoresis and chest $\mathrm{x}$-ray, were normal; furthermore, she was up-to-date with her age-appropriate cancer screening exams.

She was diagnosed with $\mathrm{MMDH}$ and began treatment with salicilic acid $8 \%$ in petrolatum ointment, resulting in transient improvement.

\section{DISAUSSION}

Since Goldstein's first description of MMDH, in 1967, at least 29 cases have been reported under different names, all comprising non-follicular digitate

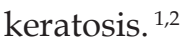

In a recent review, Caccetta et al. categorized digitate keratosis, proposing $\mathrm{MMDH}$ as a more accurate term to classify familial disseminated filiform hyperkatosis, disseminated spiked keratosis, minute aggregate keratosis, parakeratotic horns, transient

\footnotetext{
Received on 09.02.2014

Approved by the Advisory Board and accepted for publication on 10.03.2014

Work performed at the Hospitais da Universidade de Coimbra - Coimbra, Portugal.

Financial Support: None.

Conflict of Interest: None.

1 Centro Hospitalar Universitário de Coimbra - Coimbra, Portugal.

(C)2015 by Anais Brasileiros de Dermatologia
} 
postinflammatory digitate keratosis and digitate keratosis, which they considered to be synonyms for the same keratinizing disorder. ${ }^{2}$

Typical MMDH lesions include white, yellow, brown or skin-colored, milimetric spicules and flattopped, dome-shaped or crateriform papules, affecting mainly the trunk and limbs, sparing the facial and palmoplantar region. ${ }^{2}$

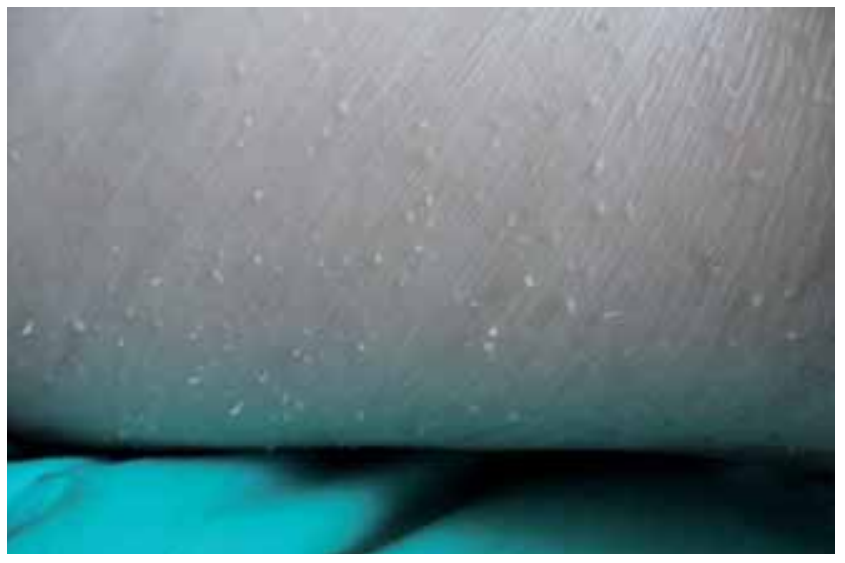

FiguRE 1: Multiple digitate filliform skin-colored hyperkeratosis occupying the inner aspect of the left thigh

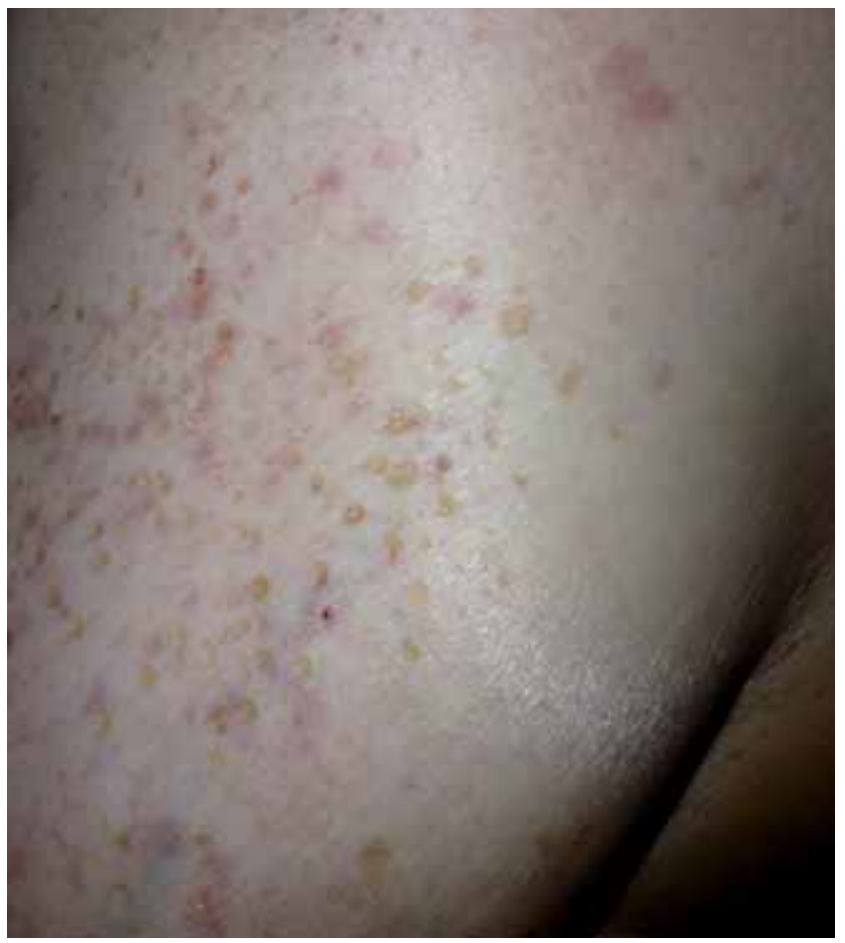

Figure 2: Multiple, 2-3 mm, honey-colored, crateriform papules distributed over the right mammary region. These lesions were present bilaterally on the anterior thoracic wall

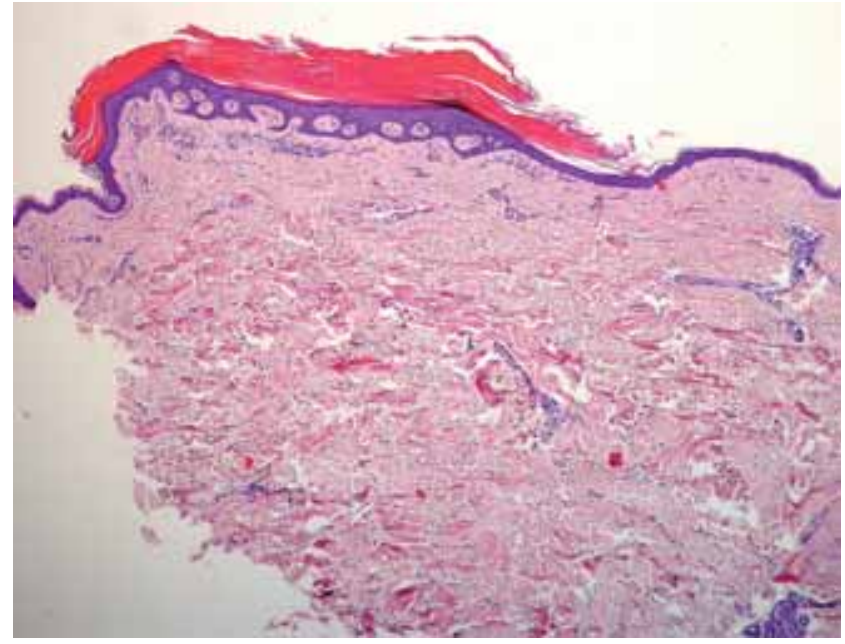

FIGURE 3: Biopsy of a crateriform papule, stained with HXE, displaying acanthosis, hyperkeratosis and a mild lymphocytic infiltrate in the upper dermis

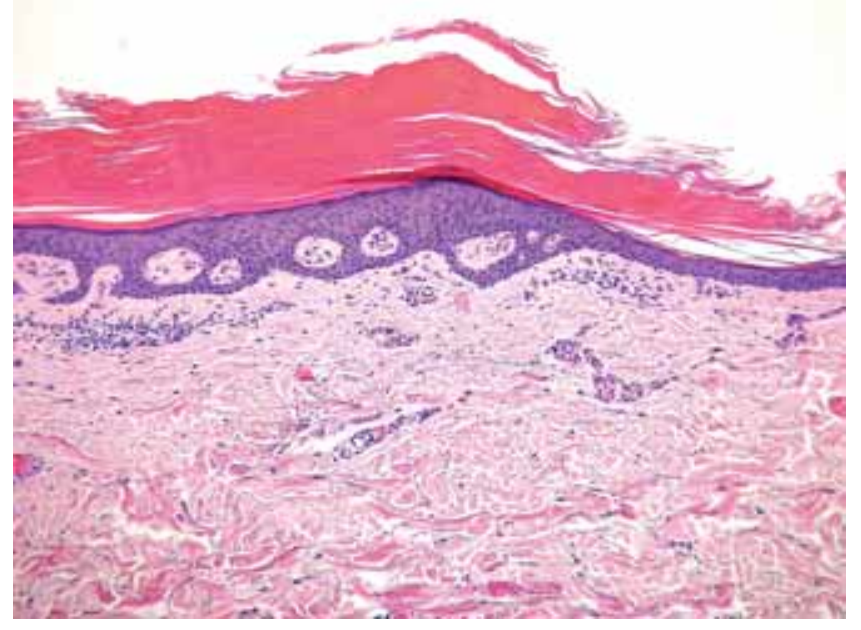

FIgURE 4: Detail of the crateriform papule's biopsy. Note the parakeratotic hyperkeratosis overlying a tented epidermis with acanthosis and a preserved granular layer

Histopathology presents focal orthokeratotic hyperkeratosis arising from a tented epidermis, and a stratum granulosum of variable thickness. Parakeratosis and epidermal invagination, as well as a superficial dermal lymphoplasmocytic infiltrate, have also been described, although more rarely. ${ }^{2}$ A constant feature that is a common denominator throughout the reported cases, is the lack of follicular involvement.

Electron microscopy shows reduced keratohyaline granules with a variable number of Odland bodies.

MMDH can present as an inherited trait in the early twenties or thirties, or appear later in life in a sporadic acquired form. ${ }^{2-5}$ The latter has been reported 
as a paraneoplastic syndrome, resolving after successful treatment of the accompanying laryngeal carcinoma. ${ }^{6}$ The former is most likely an autossomal dominant dermatosis, even though its genetic basis and pathophysiology remain unknown.

Other keratinization disorders can be entertained in the differential diagnosis of digitate keratosis, including: Kyrle's hyperkeratosis follicularis et parafollicularis, Flegel's hyperkeratosis lenticularis perstans, lichen spinulosus, phrynoderma, spiny keratoderma, arsenical keratosis, hyperkeratotic spicules and trichodysplasia spinulosa.

The first two entities can be separated from $\mathrm{MMDH}$ based on their distribution (predominantly acral), as well as their different histopathology. ${ }^{3}$

Lichen spinulosus occurs mostly in children and lesions tend to form plaques of follicular spines. Phrynoderma, due to vitamin A deficiency, also leads to generalized follicular spines, as well as xerosis. ${ }^{7}$ This follicular accentuation facilitates distinction from MMDH. Spiny keratoderma, either inherited or acquired, occurs only on the palms and soles, just like arsenic keratosis that also demonstrates a predilection for acral sites in the presence of arsenic exposure. ${ }^{8}$ This location is typically spared in MMDH.

\section{REFERENCES}

1. Goldstein N. Multiple minute digitate hyperkeratoses. Arch Dermatol. 1967;96: 692-3.

2. Caccetta TP, Dessauvagie B, McCallum D, Kumarasinghe SP. Multiple minute digitate hyperkeratosis: a proposed algorithm for the digitate keratoses. J Am Acad Dermatol. 2012;67:e49-55.

3. Balus L, Donati P, Amantea A, Breathnach AS. Multiple minute digitate hyperkeratosis. J Am Acad Dermatol. 1988;18:431-6.

4. Pimentel CL, Puig L, García-Muret MP, Fernandez-Figueras MT, Alomar A. Multiple minute digitate hyperkeratosis. J Eur Acad Dermatol Venereol. 2002;16:422-4.

5. Rubegni P, De Aloe G, Pianigiani E, Cherubini-Di Simplicio F, Fimiani M. Two sporadic cases of idiopathic multiple minute digitate hyperkeratosis. Clin Exp Dermatol. 2001;26:53-5.

6. Ferrandiz C, Savall R, Baumann E. Hiperqueratosis múltiple minuta y digitata: Un sintoma paraneoplásico? Med Cut ILA. 1978;6:279-84.

7. Torres G, Behshad R, Han A, Castrovinci AJ, Gilliam AC. "I forgot to shave my hands": a case of spiny keratoderma. J Am Acad Dermatol. 2008;58:344-8.

8. Girard C, Dereure 0, Blatière V, Guillot B, Bessis D. Vitamin A Deficiency Phrynoderma Associated with Chronic Giardiasis. Pediatr Dermatol. 2006;23:346-9.

9. Elaba Z, Hughey L, Isayeva T, Weeks B, Solovan C, Solovastru L, et al. Ultrastructural and molecular confirmation of the trichodysplasia spinulosaassociated polyomavirus in biopsies of patients with trichodysplasia spinulosa. J Cutan Pathol. 2012;39:1004-9.

10. Shuttleworth D, Graham-Brown RA, Hutchinson PE. Minute aggregate keratoses a report of three cases. Clin Exp Dermatol. 1985;10:566-71.
Hyperkeratotic spicules are harder to separate from $\mathrm{MMDH}$, since they can be follicular or non-follicular, and affect the entire integument, but these paraneoplastic keratoses contain keratin and paraprotein that appear as eosinophillic globules on histopathology.

In trichodysplasia spinulosa, which has recently been associated with polyomavirus in immunossupressed individuals, follicular spines occupy the central face, allowing for distinction from MMDH. ${ }^{9}$

Systemic or topical retinoids and other topical keratolytic agents have reportedly led to temporary improvement but lesions inexorably return upon cessation of therapy. ${ }^{1-5}$

Our case outlines not only the characteristic non-follicular, finger-like keratosis but also honey-colored crateriform papules that have seldom been described. This perhaps corresponds to the multiple aggregate keratosis that Shuttleworth differentiated from MMDH, based only on the semiology of the lesions. Our patient, however, exhibits both clinical features while maintaining typical histopathologic findings, thus strenghtening the argument that MMDH and multiple aggregate keratosis are, in fact, the same entity. ${ }^{10}$

\author{
M AILING ADDRESS: \\ M aria Inês Sampaio D antas Coutinho \\ D ermatology $D$ epartment \\ A venida Bissaya Barreto, Praceta Prof. M ota Pinto \\ 3000-075, Coimbra \\ Portugal \\ E-mail: inesdantascoutinho@gmail.com
}

H ow to cite this article: Coutinho I, Gameiro AR, Gouveia MP, Cardoso JC, Figueiredo A. Multiple Minute Digitate Hyperkeratosis - uma entidade singular. An Bras Dermatol. 2015;90 (3 Suppl 1):S153-5 